\title{
EFFECT OF THE INJECTION TIMING ON THE PERFORMANCE OF A DIESEL ENGINE USING DIESEL-BIODIESEL BLENDS
}

\author{
S. Rostami ${ }^{1}$, B. Ghobadian ${ }^{2 *}$ and M. Kiani Deh Kiani ${ }^{3}$ \\ ${ }^{1}$ Shahrekord University, Tarbiat Modares University \\ Jalal E-Aleahmad Highway, Tehran, Iran \\ ${ }^{2}$ TarbiatModares University, Jalal E-Aleahmad Highway, Tehran, Iran \\ Email: ghobadib@modares.ac.ir \\ ${ }^{3}$ Shahid Chamran University of Ahvaz, Ahvaz, Iran
}

\begin{abstract}
In this study, the effect of fuel injection timing on the performance of a diesel engine was investigated experimentally and analytically using diesel-biodiesel blends. Different experiments were carried out on the diesel engine at engine speeds of 1200 , 1600, 2000 and $2400 \mathrm{rpm}$. The injection timing was regulated for 10, 15 and 20 degree crank angle before top dead centre. The experimental results of engine torque, brakespecific fuel consumption (BSFC), cylinder pressure, and exhaust gas temperature for fuel blends of B20, B40, and B100 at different engine speeds and injection timings were recorded. The results showed that advancing the fuel injection timing for fuel blends of B20, B40, and B100 increased engine torque by approximately $2.1 \%, 2.9 \%$ and $6.3 \%$, respectively, and decreased maximum BSFC by approximately $2.7 \%, 3.3 \%$ and $6.6 \%$, respectively. Then, an artificial neural network (ANN) was used to predict engine performance. The injection timing, engine speed, and fuel blends were used as input parameters whereas engine performance parameters such as engine torque, BSFC, peak cylinder pressure, and exhaust gas temperature were used as the output parameters. The results showed that an ANN is a good tool to predict engine performance.
\end{abstract}

Keywords: Torque; Brake specific fuel consumption; Cylinder pressure; Artificial Neural Network.

\section{INTRODUCTION}

Diesel engines have recently been applied in most heavy-load mobile and in many stationary power-generation units because they can lead to greater efficiencies and higher indicated mean effective pressures due to higher compression ratios where they operate [1]. Current and future legislation on emissions require engine developers to produce cleaner and more efficient power plant systems. Nowadays, due to an increase in environmental pollution and a decrease in fossil fuels, many countries are making decisions about restricting the use of fossil fuels and using renewable fuels instead. Renewable fuels are generally produced from biological sources. Carbon dioxide produced from biofuel engines and vehicles can be absorbed by biological sources for their growth. Therefore, these fuels have a closed cycle of carbon dioxide. Biodiesel is a renewable fuel that is used in diesel engines purely or blended with common diesel [25]. Diesel and biodiesel fuels have several different properties which can decrease engine performance and increase emissions. For example, the high viscosity and surface tension of biodiesel affect atomisation by increasing the mean droplet size, which in 
turn increases spray tip penetration [6-13]. Considering the differences between diesel and biodiesel fuels, the optimum parameter of diesel engines may not seem suitable for biodiesel. Engine conditions should thus be modified based on the fuel or fuel blends to achieve optimum performance [14-16].

Several studies have investigated the effects of injection timing on engine performance for biodiesel [17-21]. Carraretto, Macor [22] observed that power and torque were increased up to almost pure diesel levels by reducing injection advance. Banapurmath, Tewari [23] compared the effects of three injection timings $\left(19^{\circ}, 23^{\circ}\right.$ and $27^{\circ} \mathrm{CA}$, crank angle) and different injection pressures on the torque (BTE) for Honge Oil Methyl Ester (HOME). They found that there was an improvement in the BTE for biodiesel by retarding injection timing and that the highest BTE occurred at 260 bar. Tsolakis, Megaritis [24] retarded injection timing by $3^{\circ} \mathrm{CA}$ on a direct injection (DI) diesel engine equipped with a pump-line-nozzle type fuel injection system. They observed that the brake specific fuel consumption increased for both B50 and pure Rapeseed Methyl Ester (RME) although the increase was not significant. Nwafor, Rice [25] investigated the effect of advanced injection timing on the performance of rapeseed oil in diesel engines. According to the test results, mechanical efficiency decreased with advanced injection timing compared to the standard injection timing at $2400 \mathrm{rpm}$. The engine was running smoothly with advanced timing compared with standard timing. Bari, Yu [26] examined the changes in the behaviour of Waste Cooking Oil (WCO) with changes in the injection timing of a DI diesel engine, compared with those of diesel fuels. The results revealed that WCO and diesel responded identically to injection timing changes. With injection timing advanced by $4^{\circ} \mathrm{CA}$, the engine produced better efficiency by 1.6 percent for WCO and by 1.1 percent for diesel. In all instances, WCO had shorter ignition delays than diesel, but the ignition delay for WCO was more sensitive to load and injection timing than that for diesel. In another study, the effects of engine operating parameters and fuel injection timing on performance and emission characteristics of Jatropha biodiesel were investigated experimentally. Advancing the injection timing (5 CA degrees, from factory settings (345 CA degrees)) caused reduction in $\mathrm{BSFC}, \mathrm{CO}, \mathrm{HC}$, and smoke and increase in BTE, peak cylinder pressure, $\mathrm{HRR}_{\max }$ and $\mathrm{NO}$ emission with Jatropha biodiesel operation. However, a 5 CA degrees retardation in injection timing caused an increase in BSFC, Carbon monoxide (CO), Hydrocarbon (HC) and smoke and a decrease in BTE, peak pressure, $\mathrm{HRR}_{\max }$ and Nitric oxide (NO). The best injection timing for Jatropha biodiesel operation with minimum BSFC, CO, HC and smoke and maximum BTE, peak pressure, and $\mathrm{HRR}_{\max }$ was found to be $340 \mathrm{CA}$ degrees [27]. The effect of varying injection timing was evaluated in terms of thermal efficiency, specific fuel consumption, power and mean effective pressure, exhaust temperature, cylinder pressure, rate of pressure rise, and the heat release rate. It was found that by retarding the injection the fuel delivery was also reduced, resulting in a slightly lower pressure rise with peak shifting towards outward stroke, reducing the negative work. In addition, retarding the injection timing by 3 degrees enhanced the thermal efficiency by about 8 percent[28].

In a study conducted on a Compression-ignition direct-injection engine using a biodiesel blend as fuel, it was clearly seen that BSEC increased by $3.11 \%$ on advancing the injection timing to $30^{\circ} \mathrm{CA}$ BTDC while it was reduced by $5 \%$ on retarding to $18^{\circ} \mathrm{CA}$ BTDC from the original injection timing of $24^{\circ} \mathrm{CA}$ BTDC. It was found that there was a $5.07 \%$ increase in brake thermal efficiency when injection timing was advanced to $30^{\circ} \mathrm{CA}$ BTDC, but about a $3.08 \%$ decrease while retarded to $18^{\circ} \mathrm{CA}$ BTDC [29]. A computational fluid dynamic investigation was carried out by Jayashankara and 
Ganesan [30] to see the effect of fuel injection timing and intake pressure on the performance of a DI diesel engine with toroidal combustion chamber configuration operating at $1000 \mathrm{rpm}$. The results showed that advanced injection timing resulted in an increase in cylinder pressure, temperature, heat release rate, cumulative heat release, and $\mathrm{NO}_{\mathrm{x}}$ emissions and retarded injection timing resulted in reverse trend.

The influence of injection timing on the performance and emission characteristics for various Karanja biodiesel-diesel blends was investigated conducting experiments on a single-cylinder diesel engine. The best injection timing for neat Karanja biodiesel based on efficiency and emission levels was 22 BTDC for the present engine [31]. Sayin and Canakci [32] carried out a study on a single-cylinder diesel engine to see the influence of injection timing on the engine performance and exhaust emissions using ethanol-blended diesel fuel. The original ignition timing gave the best results of BSFC and BTE by about $34 \%$ and $32 \%$ average value, respectively, compared to the other injection timings. Still in other studies, the performance and emission of engines were predicted by the application of Artificial Neural Networks (ANNs)[33, 34]. Parlak, Islamoglu [35] used ANNs to predict specific fuel consumption and exhaust temperature for a diesel engine. Ghobadian, Rahimi [36] analysed the diesel engine performance and exhaust emission analysis using waste cooking biodiesel fuel with an ANN. Deh Kiani, Ghobadian [37] used ANN modelling to predict the engine brake power, output torque, and exhaust emissions of a spark ignition engine. Similarly, Canakci, Erdil [38] the applicability of ANNs to predict the performance and exhaust emission values of a diesel engine fuelled with biodiesels and petroleum diesel fuels and found that there was good correlation between the ANN-predicted values and the experimental values. Srinivasa Pai and Shrinivasa Rao [39] further probed the influence of injection timing on the performance and emissions of a diesel engine using biodiesel blended with diesel. The experimental results showed that brake thermal efficiency for the advanced as well as the retarded injection timing was less than that for the normal injection timing for all sets of compression ratios. For example, when the injection timing was advanced, there was reduction in the thermal efficiency by $1 \%$ at full load for B20. On the other hand, for retarded injection timings, the thermal efficiency at full load for B20 decreased by $2.25 \%$. ANNs were used to predict the engine performance and emission characteristics of the engine. ANN results showed that there was a good correlation between the ANN-predicted values and the experimental values for various engine performance parameters and exhaust emission characteristics. The current study experimentally examined the effect of injection timing on the performance of a DI diesel engine using diesel-biodiesel fuel blends. Then, the study drew upon ANNs to establish the appropriate injection timing.

\section{MATERIALS AND METHODS}

\section{Experimental Set-up}

An overall view of the engine test-rig used in this investigation is shown in Figure 1. The engine tests were conducted on a four-stroke compression ignition engine. The specification of the engine is given in Table 1. The test engine was coupled to a Schenck W400 electric eddy current dynamometer. In-cylinder pressure was measured using a Kistler pressure transducer type 6053BB120. The engine was run at several speeds at full load. Before starting the engine, the injection timing was adjusted at 15 BTDC, which was according to the factory instructions. For adjustment, the gear wheel 
of the pump was turned against the pump shaft. After that, the adjusted gear wheel was fitted to the engine pump. The engine was tested in speed ranges of 1200-2400 rpm with the interval of $400 \mathrm{rpm}$. During the experiments, brake torque, in-cylinder pressure, exhaust gas temperature, and BSFC were recorded by a PC computer. Similarly, these measurements were repeated for different blends of diesel and biodiesel fuels.

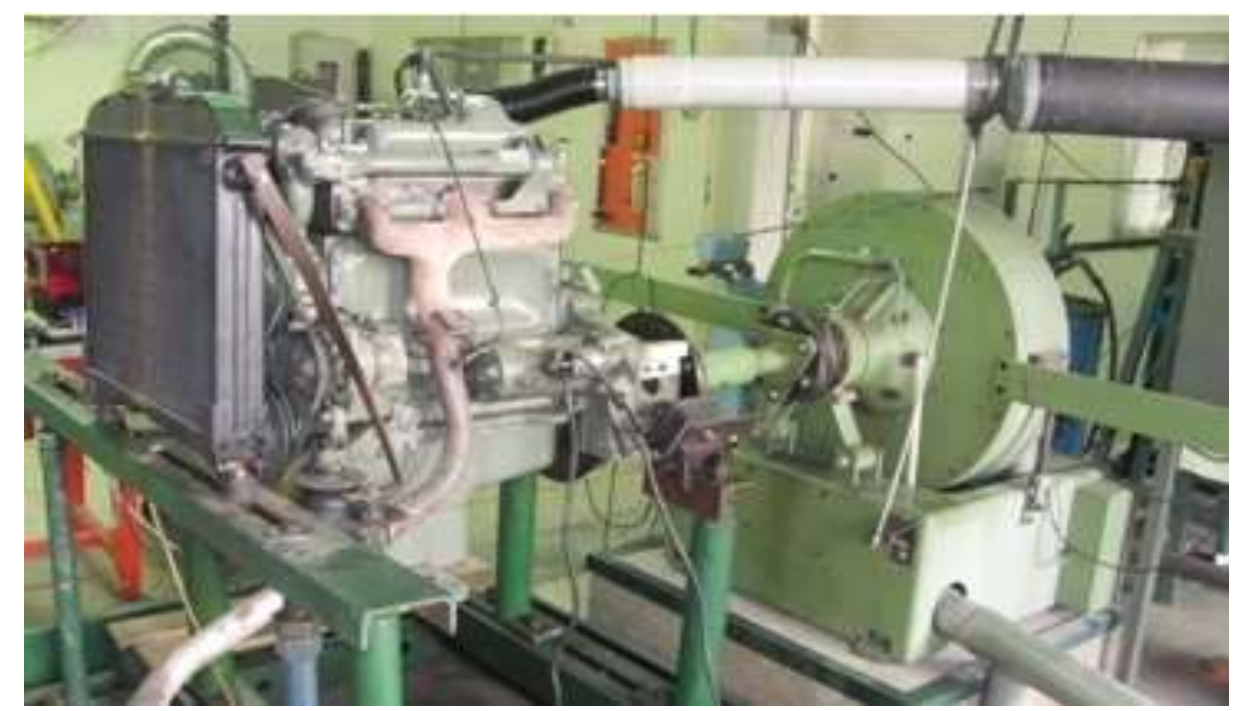

Figure 1. Experimental set-up.

Table 1. Specifications of the OM314 diesel engine.

\begin{tabular}{ll}
\hline No. of cylinders & 4 \\
\hline Bore & $97 \mathrm{~mm}$ \\
Stroke & $128 \mathrm{~mm}$ \\
Swept volume & $3780 \mathrm{~cm}^{3}$ \\
Compression ratio & $17: 1$ \\
Max .power (with gas oil) & $85 \mathrm{hp}(63 \mathrm{~kW})$ \\
Max. torque (with gas oil) & $235 \mathrm{Nm}$ \\
Max. speed & $2800 \mathrm{rpm}$ \\
Injection pressure & $200 \mathrm{bar}$ \\
Fuel injection timing & $15 \mathrm{BTDC}$ \\
Cooling system & Water cooled \\
\hline
\end{tabular}

\section{Biodiesel Fuel}

The environment-friendly biodiesel fuel produced from waste vegetable cooking oil and its blends with diesel were employed in this study. Some of the important fuel properties of waste vegetable cooking oil biodiesel (B100) and diesel fuel were determined as per the ASTM standards and procedures, which are summarised in Table 2. The waste vegetable oil biodiesel was added to diesel fuel at 20 and 40 percent ratios and then it was used as fuel for the diesel engine being tested. 
Table 2. Important properties of diesel and biodiesel fuels.

\begin{tabular}{lllll}
\hline Property & Method & Units & Diesel & Biodiesel \\
\hline Flash point, closed cup & D 93 & ${ }^{\circ} \mathrm{C}$ & 64 & 182 \\
Pour point & D 97 & ${ }^{\circ} \mathrm{C}$ & 0 & 3 \\
Kinematical viscosity, $40{ }^{\circ} \mathrm{C}$ & D 445 & $\mathrm{mm}^{2} / \mathrm{s}$ & 4.03 & 4.15 \\
Sulphated ash & D 874 & wt.\% & & 0.00 \\
Total sulphur & D 5453 & wt.\% & 0.0500 & 0.0018 \\
Copper strip corrosion & D 130 & & $1 \mathrm{a}$ & $1 \mathrm{a}$ \\
Cloud point & D 2500 & ${ }^{\circ} \mathrm{C}$ & 2 & 0 \\
\hline
\end{tabular}

\section{Neural Network Design}

To get the best prediction by the network, several structures were evaluated and trained using the experimental data. Back-propagation is a network created by generalising the Widrow-Hoff learning rule to multiple-layer networks and nonlinear differentiable transfer functions. Input vectors and the corresponding target vectors are used to train a network until it can approximate a function. Networks with biases, a sigmoid layer, and a linear output layer are capable of approximating any function with a finite number of discontinuities. Standard back-propagation is a gradient descent algorithm, as is the Widrow-Hoff learning rule, in which the network weights are moved along the negative of the gradient of the performance function. Each neuron computes a weighted sum of its $n$ input signals, $x j$, for $j=1,2, \ldots n$, and then applies a nonlinear activation function to produce an output signal $y[29]$ :

$$
y=\varphi\left(\sum_{j=1}^{n} w_{i} x_{i}\right)
$$

The performance of the network can be evaluated by comparing the error obtained from converged neural network runs and the measured data. The error was calculated at the end of training and testing processes based on the differences between targeted and calculated outputs. The back-propagation algorithm minimises an error function defined by the average of the sum square difference between the output of each neuron in the output layer and the desired output. The error function can be expressed as [29]:

$$
E=\frac{1}{p} \sum_{p} \sum_{k}\left(d_{p k}-o_{p k}\right)^{2}
$$

where $p$ is the index of the $p$ training pairs of vectors, $k$ is the index of elements in the output vector, $d_{p k}$ is the $k$ th element of the $p$ th desired pattern vector, and $o_{p k}$ is the $k$ th element of the output vector when pattern $p$ is presented as input to the network. Minimising the cost function represented in Eq.(2) results in an updating rule to adjust the weights of the connections between neurons. In this research, the Back-Propagation Neural Networks (BPNN) were trained using the training sets formed by including 80 percent of the data. After training, the BPNNs were tested using 20 percent of the data. There were three input and four output parameters in the experimental tests. The three 
input variables were engine speed in rpm, injection timing, and the percentage of biodiesel blending with the conventional diesel fuel. The four outputs for evaluating engine performance were engine torque in $\mathrm{Nm}, \mathrm{BSFC}$ in $\mathrm{gr} / \mathrm{kWh}$, exhaust gas temperature, and peak pressure. Therefore, the input layer consisted of 3 neurons and the output layer had 4 neurons.

The number of hidden layers and neurons within each layer can be designed by the complexity of the problem and data set. In this study, the number of hidden layers varied from one to two. To ensure that each input variable provided an equal contribution in the ANN, the inputs of the model were pre-processed and scaled into a common numeric range $[-1,1]$. The activation function for the hidden layer was selected to be logsig. A linear function was best suited for the output layer. This arrangement of functions in function approximation problems or modelling is common and yields better results. However, many other networks with several functions and topologies were examined, which are briefly shown in Table 3. The network topography comprises the number of neurons in the hidden layer and output layer. As depicted in Table 3, several topographies were examined, but the one-hidden-layer networks, e.g. $[15,4]$, which imply 15 neurons for the hidden layer and 4 neurons for the output layer, were selected. Three criteria were selected to evaluate the networks, and ultimately find the optimum one among them. The training and testing performance (MSE) were chosen to be the error criterion. The network complexity and size are very important since the selection of hidden layers as well as neurons in the hidden layers should be well-adjusted to the network inputs. The computer program MATLAB R2009a, Neural Network Toolbox, was used for ANN design.

Table 3. Summary of ANN models' evaluations.

\begin{tabular}{cccc}
\hline Activation function & $\begin{array}{c}\text { Net } \\
\text { Topography }\end{array}$ & Test error & R (test) \\
\hline Log/Lin & $(5,4)$ & 0.00031 & 0.94997 \\
Log/Lin & $(10,4)$ & 0.00018 & 0.96819 \\
Tan/Lin & $(15,4)$ & 0.00014 & 0.99994 \\
Tan/Lin & $(20,4)$ & 0.00027 & 0.98947 \\
Log/Lin & $(5,10,4)$ & 0.0012 & 0.97164 \\
Log/Lin & $(5,15,4)$ & 0.00018 & 0.93791 \\
Log/Tan/Lin & $(10,15,4)$ & 0.00018 & 0.90537 \\
Log/Tan/Lin & $(10,20,4)$ & 0.01020 & 0.99892 \\
Log/Tan/Lin & $(15,15,4)$ & 0.00020 & 0.97989 \\
Log/Log/Tan & $(15,20,4)$ & 0.00033 & 0.96825 \\
\hline
\end{tabular}

RESULTS AND DISCUSSION

\section{The Effect of Fuel Injection Timing on Engine Torque}

To determine the effect of engine fuel injection timing on engine torque for fuel blends of B20, B40 and B100, the engine torque at different engine speeds and fuel injection timings for each fuel blend were measured separately. The results are shown in Figure 2. The maximum torque at an injection timing of 15 BTDC for fuel B20 was 192.5 Nm and it occurred at $2000 \mathrm{rpm}$. By advancing the injection timing to 20 BTDC, the maximum value of torque increased to $196.5 \mathrm{Nm}$. Maximum torque at $10 \mathrm{BTDC}$ 
decreased to $187 \mathrm{Nm}$. Maximum torque in the case of B40 at $15 \mathrm{BTDC}$, that is, the standard injection timing of the engine, was $192 \mathrm{Nm}$ and occurred at $1600 \mathrm{rpm}$. With earlier injection timing, the maximum torque was $197.5 \mathrm{Nm}$ and this torque was measured at $1600 \mathrm{rpm}$. At retarded injection timing, the maximum torque increased to $186 \mathrm{Nm}$. For pure biodiesel at standard injection timing, the maximum torque was 183.5 $\mathrm{Nm}$ and occurred at $1600 \mathrm{rpm}$. For advanced injection timing, the maximum torque increased to $197 \mathrm{Nm}$. With retarding the injection timing, the maximum torque decreased to $177 \mathrm{Nm}$. As can be seen in Figure 2, the variations of engine torque at different injection timings have the same trend for all fuels. Generally, advancing the injection timing of fuel causes an increase in the average torque and retarding the injection timing of fuel causes the average torque of the engine to decrease. By advancing the injection timing, the peak pressure takes place closer to BTDC and therefore produces a higher mean effective pressure, and the value of engine torque increases. On the other hand, later injection causes later combustion; thus, the pressure rises only when the cylinder volume is expanding rapidly. The result is a reduced mean effective pressure and in turn a decreased engine torque value.

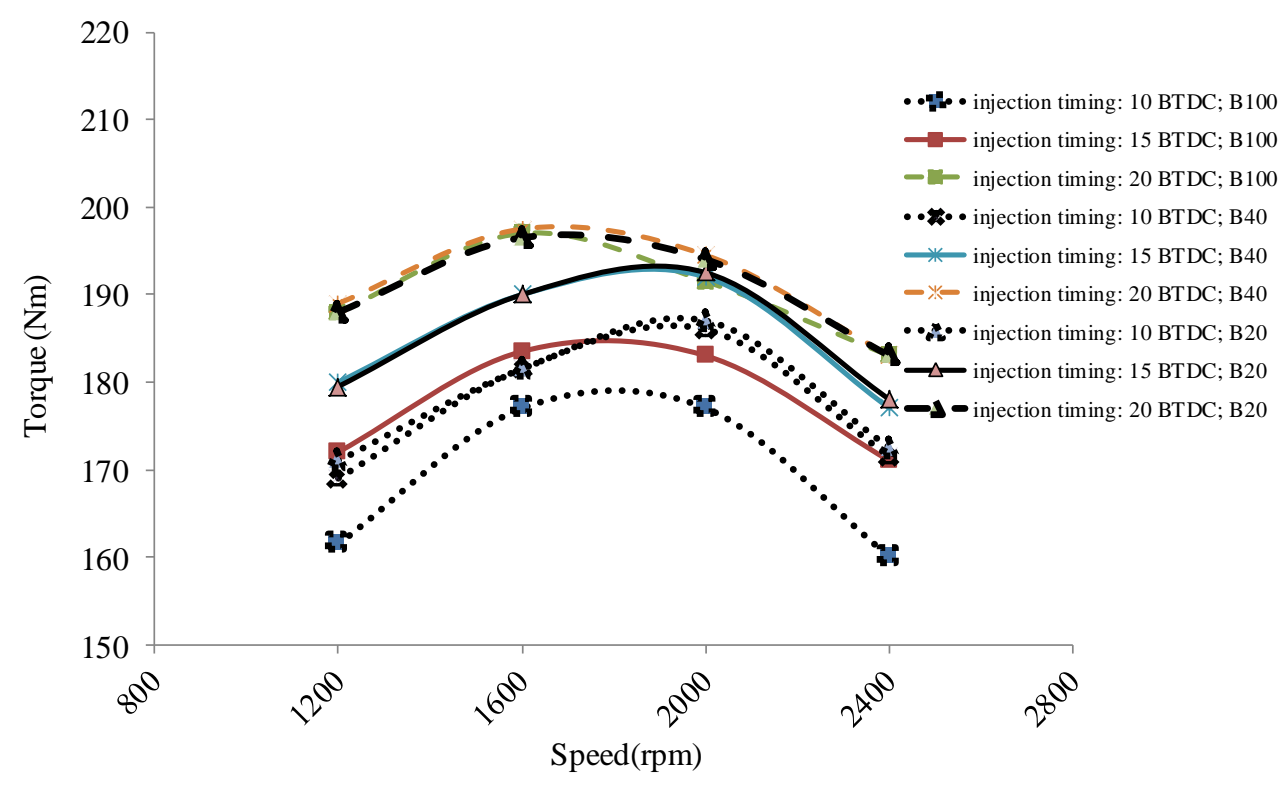

Figure 2. The engine torque versus engine speed.

\section{The Effect of Fuel Injection Timing on BSFC}

BSFC indicates the fuel level required to produce one $\mathrm{kW}$ of power for one hour when the engine is operating. To determine the effect of fuel injection timing on BSFC for fuel blends of B20, B40 and B100, the BSFC of the engine at various engine speeds and different fuel injection timings for each fuel was measured separately. The results are shown in Figure 3. In the case of B20 at the standard injection timing, maximum BSFC was $290 \mathrm{gr} / \mathrm{kWh}$. By advancing the fuel injection timing into the combustion chamber, this value was reduced to $282 \mathrm{gr} / \mathrm{kWh}$ (a $2.7 \%$ reduction). In the case of B40 at the standard injection timing, maximum BSFC was $297 \mathrm{gr} / \mathrm{kWh}$. By advancing the injection timing to 20 BTDC, maximum BSFC decreased by about $3.3 \%$, which was equal to 287 $\mathrm{gr} / \mathrm{kWh}$. During the application of B100 at 15 BTDC, the maximum BSFC of the engine was $330 \mathrm{gr} / \mathrm{kWh}$. By advancing the fuel injection timing to about 5 degree crank angle, 
BSFC decreased to approximately $6.6 \%$ and was equal to $309 \mathrm{gr} / \mathrm{kWh}$. As for biodiesel and its blends with diesel fuel, with retarding the fuel injection timing compared to the standard injection timing, it was observed that BSFC increased. Advancing the fuel injection timing reduced the BSFC. This is due to the fact that the soybean oil-based WCO used in this study exhibits shorter ignition delay compared to diesel fuel [40]. Therefore, for biodiesel and its blends with diesel fuel, with retarding the fuel injection timing compared with the standard injection timing BSFC increased. Nwafer et al. [25] has carried out a similar study with rapeseed oil that has a longer ignition delay than diesel. Their research showed that BSFC increased with advanced fuel injection timing.

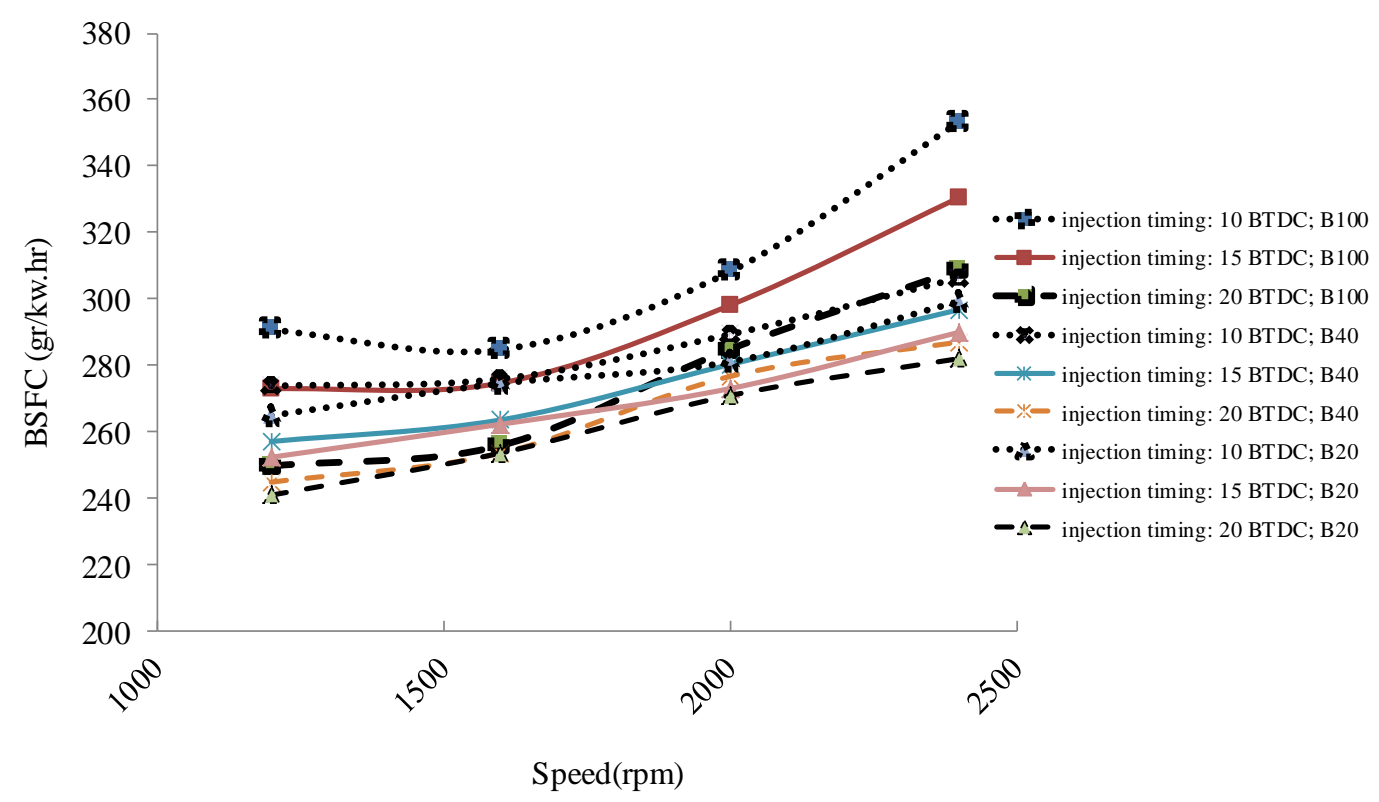

Figure 3.The engine BSFC versus engine speed.

\section{The Effect of Fuel Injection Timing on In-Cylinder Pressure}

Figure 4 shows the in-cylinder pressure versus crank angle for different fuels in different fuel injection timings at $1600 \mathrm{rpm}$. As Figure 4 shows, advancing fuel injection timing increases the peak cylinder pressure for B20, B40, and B100. The reason is that fuel injection timing is a major parameter in a diesel engine that affects engine combustion [41]. The state of air into which the injected fuel changes as the injection timing is varied affects the ignition delay. When fuel injecting occurs before the standard injection timing, the pressure and temperature of the charged air in the cylinder is less than that of the fuel when it is injected at standard injection timing [42]. Thus, ignition delay of the injected fuel extends further and, simultaneously, the penetration of fuel spray enhances. As a consequence, the reaction between fuel and air improves, which prepares a good mixture for burning. When the combustion starts, the rate of heat release increases in the premixed or rapid combustion phase of the combustion process due to the suitability of the mixture of air and fuel [43]. Most of the energy is released inthe first phase of combustion and hence the peak pressure of the cylinder takes place close to BTDC and increases [42]. Moreover, by advancing the fuel injection timing, the fuel spray can promote the in-cylinder turbulence and help with mixing. When the injection timing is retarded, the fuel is injected into charged air that has a high temperature and pressure. As a result, the ignition delay decreases and the 
fuel does not get enough time to mix well with the air and therefore when combustion starts, the rate of heat release decreases in the premixed combustion phase of the combustion process and the peak pressure of the cylinder decreases and occurs far away from BTDC.

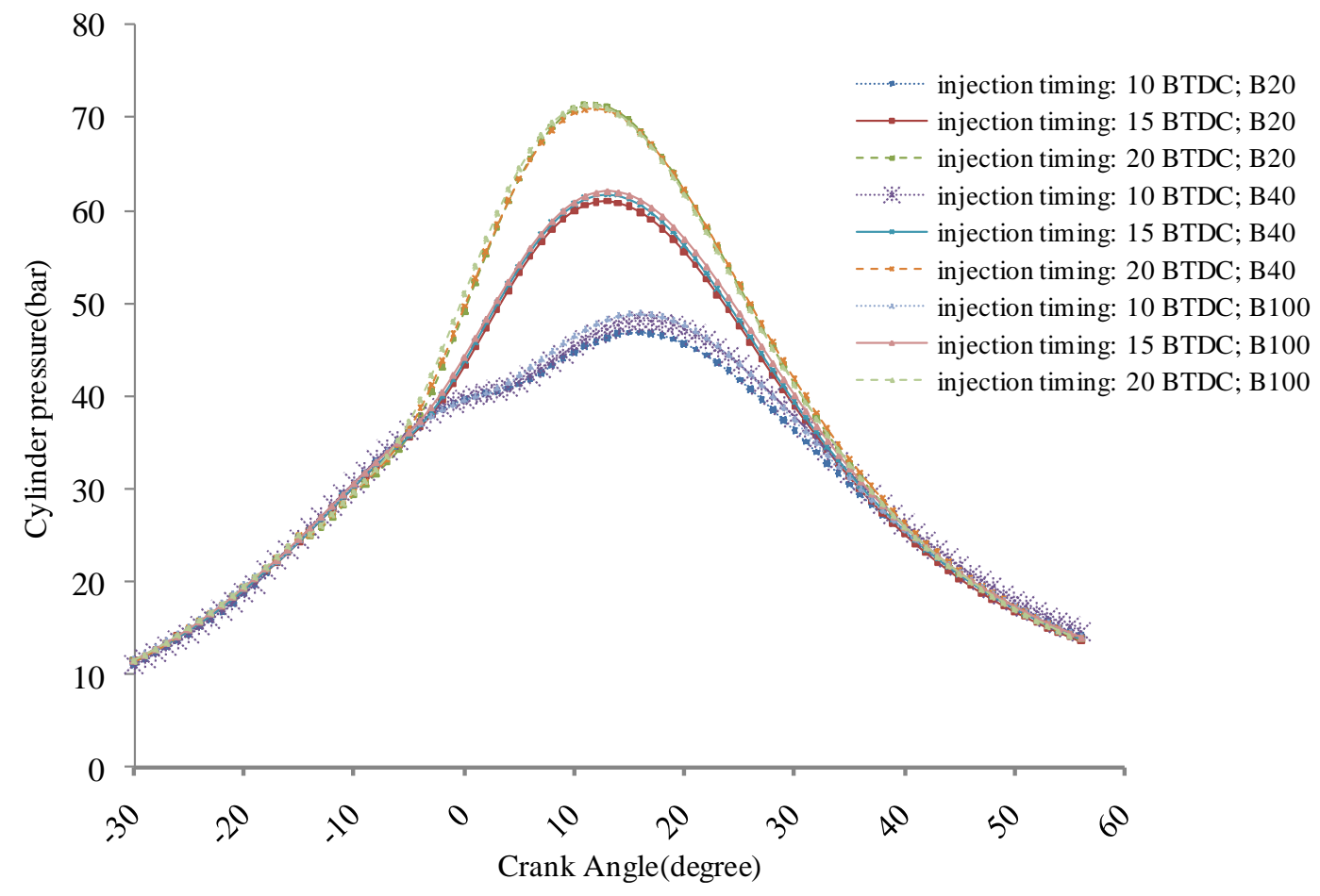

Figure 4. The engine cylinder pressure versus crank angle.

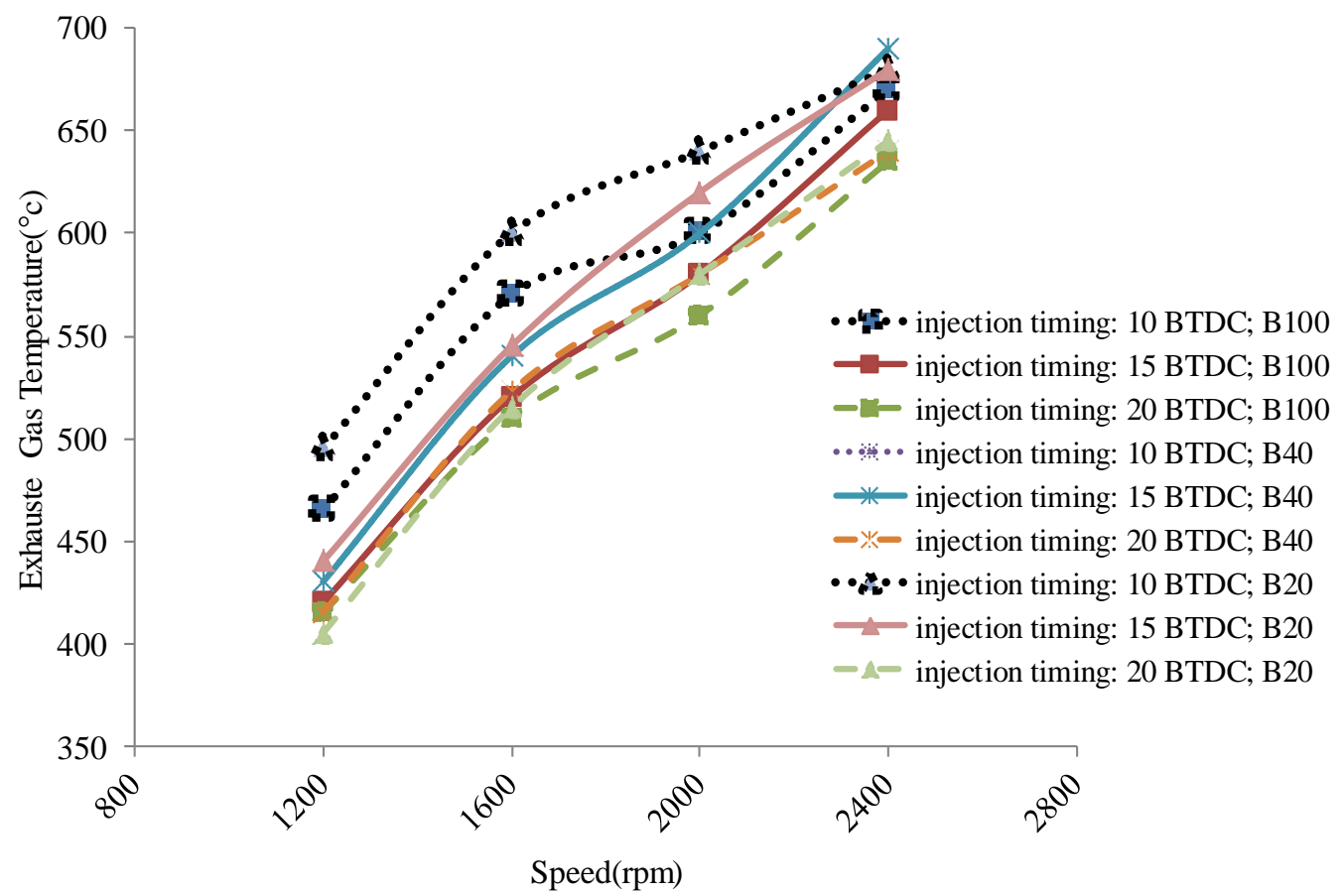

Figure 5. The exhaust gas temperature versus engine speed. 


\section{The Effects of Fuel Injection Timing on Exhaust Gas Temperature}

Figure 5 compares the exhaust gas temperature of B20, B40, and B100 at different injection timings. The exhaust gas temperature decreases for all fuels by advancing the injection timing, which is an indication of complete combustion. The reason is that with advancing the injection timing, a larger part of the fuel is burnt in the first phase of the combustion process, which can be observed from the diagrams of in-cylinder pressure [44]. This is due to less heat loss, as is evident from the low BSFC. The exhaust gas temperature is found to be higher with retarded fuel injection timing for 10 BTDC, which is an indication of incomplete combustion.
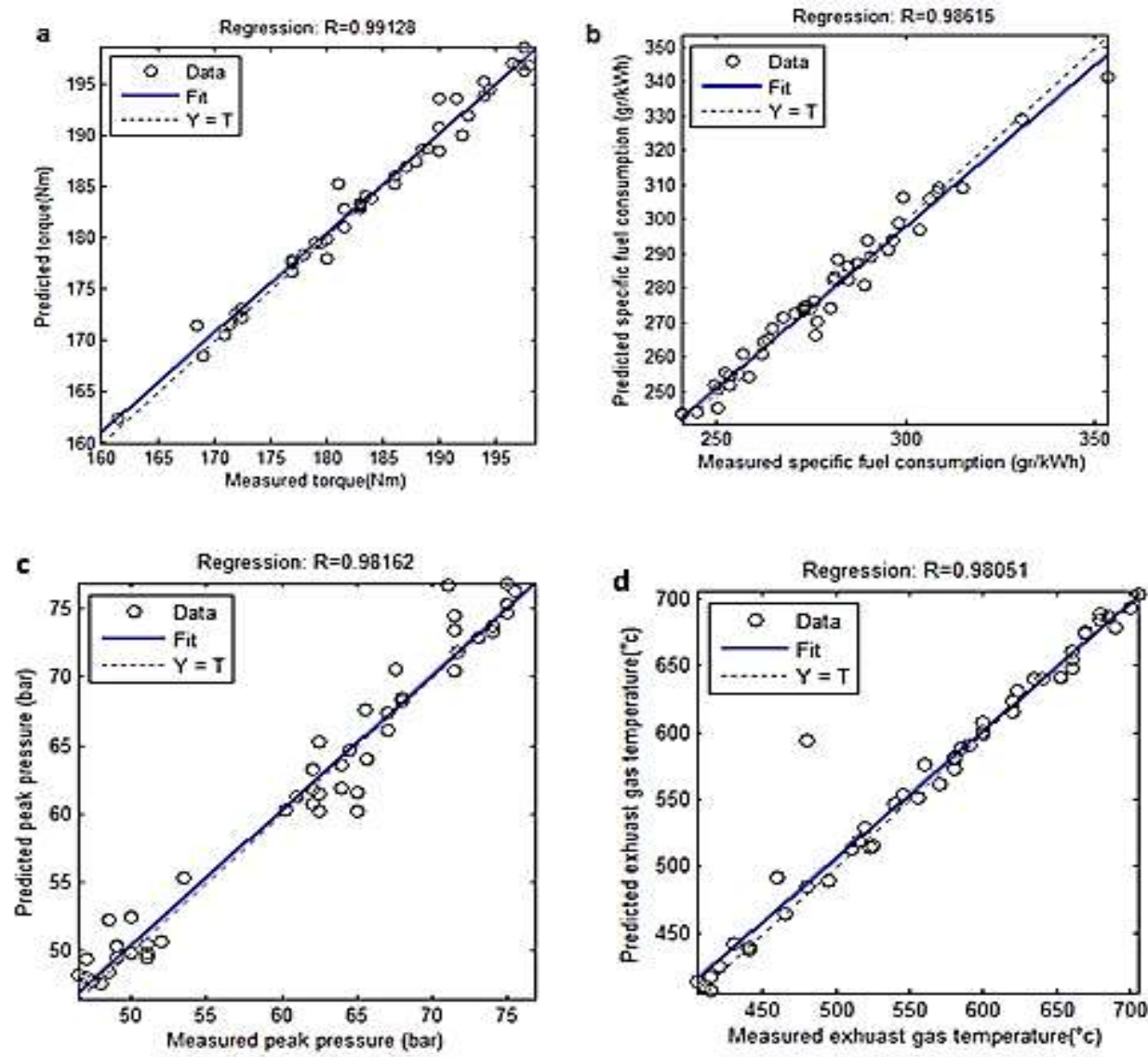

Figure 6. The predicted engine outputs versus the measured values for(a) engine torque; (b) BSFC; (c) Peak pressure; (d) Gas exhaust temperature.

\section{Modelling with ANN}

The number of hidden layers and neurons within each layer can be determined by the complexity of the problem and data set. In this study, the network was decided to consist of one hidden layer with 15 neurons. The criterion $\mathrm{R}$ was selected to evaluate the networks and find the optimum solution. The complexity and size of the network were also important factors, and therefore smaller ANNs had to be selected. A regression analysis between the network response and the corresponding targets was performed to investigate the network response in more detail. Different training algorithms were 
tested and Levenberg-Marquardt (trainlm) was selected. The R-values in Table 3 represents the correlation coefficients between the outputs and targets. The R-value did not increase beyond 15 neurons in the hidden layers. Consequently, the network with 15 neurons in the hidden layers would be considered satisfactory. The results showed that the back-propagation training algorithm was sufficient for predicting engine torque, BSFC, exhaust gas temperature, and peak pressure components for different engine speeds, injection timings, and different fuel-blend ratios. The predicted values versus experimental values for the experimental parameters are indicated in Figure 6. There is a high correlation between the predicted values by the ANN model and the measured values resulting from the experimental tests, implying that the model succeeded in predicting engine performance. It is understood from Figure 6 that one can definitely predict engine torque, BSFC, peak pressure and exhaust gas temperature separately using the designed network with correlation coefficients of $0.99128,0.98615,0.98162$ and 0.98051 , respectively. Generally, the ANN has the advantage of being fast, accurate, and reliable in the prediction or approximation affairs, especially when numerical and mathematical methods fail. There is also a significant simplicity in using the ANN due to its ability to deal with multivariate and complicated problems.

\section{CONCLUSIONS}

In this study, the effect of fuel injection timing on the performance of a DI diesel engine was investigated experimentally and analytically using environmentally-friendly dieselbiodiesel fuel blends. Based on the findings, the following conclusions are made:

i) With advancing the engine fuel injection timing, the peak cylinder occurred closer to BTDC, therefore, the engine produced a higher mean effective pressure and the value of the engine torque increased.

ii) For biodiesel and its blends with diesel fuel, BSFC increased by retarding the fuel injection timing compared with standard injection timing. On the other hand, advancing the fuel injection timing reduced BSFC.

iii) The exhaust gas temperature decreased for all fuel blend ratios by advancing the engine fuel injection timing, indicating complete combustion. The exhaust gas temperature was found to be higher than the usual fuel injection timing setting with retarding the fuel injection timing to 10 BTDC, indicating incomplete combustion.

iv) The ANN can predict engine torque, BSFC, peak pressure and exhaust gas temperature separately with correlation coefficients of $0.99128,0.98615$, 0.98162 and 0.98051 , respectively, indicating reasonable estimates.

\section{ACKNOWLEDGMENTS}

The authors would like to thanks to Tarbiat Modares University to providing laboratory facilities and financial assistance.

\section{REFERENCES}

[1] Narayana Reddy J, Ramesh A. Parametric studies for improving the performance of a Jatropha oil-fuelled compression ignition engine. Renewable Energy. 2006;31:1994-2016. 
[2] Aksoy F. The effect of opium poppy oil diesel fuel mixture on engine performance and emissions. International Journal of Environmental Science \& Technology. 2011;8:57-62.

[3] Golovitchev VI, Yang J. Construction of combustion models for rapeseed methyl ester bio-diesel fuel for internal combustion engine applications. Biotechnology advances. 2009;27:641-55.

[4] Kegl B. Influence of biodiesel on engine combustion and emission characteristics. Applied energy. 2011;88:1803-12.

[5] Yuan W, Hansen A. Computational investigation of the effect of biodiesel fuel properties on diesel engine NOx emissions. International Journal of Agricultural and Biological Engineering. 2009;2:41-8.

[6] Celikten I. An experimental investigation of the effect of the injection pressure on engine performance and exhaust emission in indirect injection diesel engines. Applied Thermal Engineering. 2003;23:2051-60.

[7] Demirbas A. Progress and recent trends in biofuels. Progress in energy and combustion science. 2007;33:1-18.

[8] Ejim C, Fleck B, Amirfazli A. Analytical study for atomization of biodiesels and their blends in a typical injector: surface tension and viscosity effects. Fuel. 2007;86:1534-44.

[9] Forson F, Oduro E, Hammond-Donkoh E. Performance of jatropha oil blends in a diesel engine. Renewable energy. 2004;29:1135-45.

[10] Monyem A, H Van Gerpen J. The effect of biodiesel oxidation on engine performance and emissions. Biomass and Bioenergy. 2001;20:317-25.

[11] Murillo S, Miguez J, Porteiro J, Granada E, Moran J. Performance and exhaust emissions in the use of biodiesel in outboard diesel engines. Fuel. 2007;86:176571.

[12] Raheman H, Phadatare A. Diesel engine emissions and performance from blends of karanja methyl ester and diesel. Biomass and Bioenergy. 2004;27:393-7.

[13] Ramadhas A, Muraleedharan C, Jayaraj S. Performance and emission evaluation of a diesel engine fueled with methyl esters of rubber seed oil. Renewable energy. 2005;30:1789-800.

[14] Rahim R, Mamat R, Taib MY, Abdullah AA. Influence of fuel temperature on a diesel engine performance operating with biodiesel blended. Journal of Mechanical Engineering and Sciences. 2012;2:226-36.

[15] Ghobadian B, Najafi G, Nayebi M. A semi-empirical model to predict diesel engine combustion parameters. Journal of Mechanical Engineering and Sciences. 2013;4:373-82.

[16] Yusop AF, Mamat R, Mat Yasin MH, Ali OM. Effects of particulate matter emissions of diesel engine using diesel-methanol blends. Journal of Mechanical Engineering and Sciences. 2014;6:959-67.

[17] Sundar Raj C, Sendilvelan S. Effect of oxygenated hydrocarbon additives on exhaust emission of a diesel engine. International Journal of Automotive and Mechanical Engineering. 2010;2:144-56.

[18] Azad AK, Ameer Uddin SM, Alam MM. A comprehensive study of DI diesel engine performance with vegetable oil: an alternative boi-fuel source of energy. International Journal of Automotive and Mechanical Engineering. 2012;5:57686. 
[19] Soon LB, M. Rus AZ, Hasan S. Continuous biodiesel production using ultrasound clamp on tubular reactor. International Journal of Automotive and Mechanical Engineering. 2013;8:1396-405.

[20] Yusaf T, Hamawand I, Baker P, Najafi G. The effect of methanol-diesel blended ratio on CI engine performance. International Journal of Automotive and Mechanical Engineering. 2013;8:1385-95.

[21] Abbaszadeh A, Ghobadian B, Najafi G, Yusaf T. An experimental investigation of the effective parameters on wet washing of biodiesel purification. International Journal of Automotive and Mechanical Engineering. 2014;9:152537.

[22] Carraretto C, Macor A, Mirandola A, Stoppato A, Tonon S. Biodiesel as alternative fuel: Experimental analysis and energetic evaluations. Energy. 2004;29:2195-211.

[23] Banapurmath N, Tewari P, Hosmath R. Effect of biodiesel derived from Honge oil and its blends with diesel when directly injected at different injection pressures and injection timings in single-cylinder water-cooled compression ignition engine. Proceedings of the Institution of Mechanical Engineers, Part A: Journal of Power and Energy. 2009;223:31-40.

[24] Tsolakis A, Megaritis A, Wyszynski M, Theinnoi K. Engine performance and emissions of a diesel engine operating on diesel-RME (rapeseed methyl ester) blends with EGR (exhaust gas recirculation). Energy. 2007;32:2072-80.

[25] Nwafor O, Rice G, Ogbonna A. Effect of advanced injection timing on the performance of rapeseed oil in diesel engines. Renewable Energy. 2000;21:43344.

[26] Bari S, Yu C, Lim T. Effect of fuel injection timing with waste cooking oil as a fuel in a direct injection diesel engine. Proceedings of the Institution of Mechanical Engineers, Part D: Journal of Automobile Engineering. 2004;218:93-104.

[27] Ganapathy T, Gakkhar R, Murugesan K. Influence of injection timing on performance, combustion and emission characteristics of Jatropha biodiesel engine. Applied energy. 2011;88:4376-86.

[28] Jindal S. Effect of injection timing on combustion and performance of a direct injection diesel engine running on Jatropha methyl ester. The International Journal of Energy and Environment. 2011;2:113-22.

[29] Pandian M, Sivapirakasam S, Udayakumar M. Influence of injection timing on performance and emission characteristics of naturally aspirated twin cylinder CIDI engine using bio-diesel blend as fuel. International Journal of Recent Trends in Engineering. 2009;1:113-7.

[30] Jayashankara B, Ganesan V. Effect of fuel injection timing and intake pressure on the performance of a DI diesel engine-A parametric study using CFD. Energy Conversion and Management. 2010;51:1835-48.

[31] Maheshwari N, Balaji C, Ramesh A. A nonlinear regression based multiobjective optimization of parameters based on experimental data from an IC engine fueled with biodiesel blends. Biomass and bioenergy. 2011;35:2171-83.

[32] Sayin C, Canakci M. Effects of injection timing on the engine performance and exhaust emissions of a dual-fuel diesel engine. Energy Conversion and Management. 2009;50:203-13.

[33] Cay Y. Prediction of a gasoline engine performance with artificial neural network. Fuel. 2013;111:324-31. 
[34] Kumar DV, Kumar PR, Kumari MS. Prediction of Performance and Emissions of a Biodiesel Fueled Lanthanum Zirconate Coated Direct Injection Diesel Engine Using Artificial Neural Networks. Procedia Engineering. 2013;64:9931002.

[35] Parlak A, Islamoglu Y, Yasar H, Egrisogut A. Application of artificial neural network to predict specific fuel consumption and exhaust temperature for a diesel engine. Applied Thermal Engineering. 2006;26:824-8.

[36] Ghobadian B, Rahimi H, Nikbakht A, Najafi G, Yusaf T. Diesel engine performance and exhaust emission analysis using waste cooking biodiesel fuel with an artificial neural network. Renewable Energy. 2009;34:976-82.

[37] Deh Kiani MK, Ghobadian B, Tavakoli T, Nikbakht A, Najafi G. Application of artificial neural networks for the prediction of performance and exhaust emissions in SI engine using ethanol-gasoline blends. Energy. 2010;35:65-9.

[38] Canakci M, Erdil A, Arcaklioğlu E. Performance and exhaust emissions of a biodiesel engine. Applied energy. 2006;83:594-605.

[39] Srinivasa Pai P, Shrinivasa Rao B. Artificial Neural Network based prediction of performance and emission characteristics of a variable compression ratio $\mathrm{CI}$ engine using WCO as a biodiesel at different injection timings. Applied Energy. 2011;88:2344-54.

[40] Lee D, Jho Y, Lee CS. Effects of Soybean and Canola Oil-Based Biodiesel Blends on Spray, Combustion, and Emission Characteristics in a Diesel Engine. Journal of Energy Engineering. 2013.

[41] Puhan S, Jegan R, Balasubbramanian K, Nagarajan G. Effect of injection pressure on performance, emission and combustion characteristics of high linolenic linseed oil methyl ester in a DI diesel engine. Renewable Energy. 2009;34:1227-33.

[42] Raheman H, Ghadge S. Performance of diesel engine with biodiesel at varying compression ratio and ignition timing. Fuel. 2008;87:2659-66.

[43] Mani M, Nagarajan G. Influence of injection timing on performance, emission and combustion characteristics of a DI diesel engine running on waste plastic oil. Energy. 2009;34:1617-23.

[44] Rao P. Effect of properties of Karanja methyl ester on combustion and NOx emissions of a diesel engine. Journal of Petroleum Technology and Alternative Fuels. 2011;2:63-75. 